\title{
MANAGEMENT NOTES
}

\section{Cattle Dips Are Used as a Tool for Range Management in Masailand, Tanzania}

\section{E. G. VAN VOORTHUIZEN}

Range Ecologist, Masailand, Near East

Foundation-U.S.AID/Government of Tanzania, Arusha, Tanzania.

\section{Highlight}

In many areas of east Africa cattle dips are needed to combat tickborne diseases. Currently the dips are installed near permanent water supplies and easy access roads, which leads to concentrations of livestock and overgrazing. However, with better management planning dips may be used as a tool to open new grazing areas and to increase the carrying capacity of the region. This article refers to the existing Tanzanian government programs for the pastoral peoples located mainly in the Masai district of northern Tanzania.

The object of the government dipping program is to dip as many cattle as possible to combat tickborne diseases. However, the Masai Range Development Commission officers believe that grazing management can be improved by locating the dips further apart where range conditions justify enough concentration of cattle for dipping. Previous surveys undertaken in Masailand, Tanzania indicate that not only are there large portions of rangeland which are not fully utilized but that cattle production from this vast area is only a fraction of its potential. The main reason is that diseases and the lack of permanent water maintains the stocking rate well below the potential carrying capacity. Masai herdsmen have traditionally combatted disease problems by moving cattle away from infected areas.

Five common species (Table 1) of ticks carry diseases which kill $60-80 \%$ of the calves before the age of nine months (Walker, 1962). East Coast Fever is the major one resulting in a $30 \%$ loss of the calf crop. Mrema (1968) states that one tick can suck more than a quarter cc of blood per day and some cattle harbor many hundreds of them. Tick bite wounds are numerous on the dewlap, ears, perineum, udders, tails and sternum of cattle and these result in secondary infections.

Tick surveys show that one beast can harbor up to 2000 ticks on its hide. This means that there are millions of ticks per square mile of rangeland. Tropical rangelands with tall grass species such as Themeda triandra, Pennisetum mezianum, Cynodon plectostachyus and Hyparrhenia sp. become a suitable habitat for the propagation of the tick. Conditions of

${ }^{1}$ Received October 27, 1970; accepted for publication January 16,1971 . understocking due to diseases favor the lifecycle of ticks. The larvae, often referred to as "pepper ticks" climb up the stems of grasses and may congregate in small clusters waiting to attach to a passing animal.

The Masai herdsmen annually resort to burning large stretches of rangeland to reduce the incidence of ticks but this practice lowers the grazing capacity. It is at best of only temporary value for tick control.

The best known solution to the low cattle populations is to prevent death from tickborne diseases by dipping. Also, better range management can be achieved by placing the dips in locations where optimum range use can be obtained.

\section{Management Application}

Introduction of a region-wide dipping program with support from the district councils was necessary. The cattle owners were eager to support the program as Mrema (1969) shows in his report by the self-help contributions by herders in the Bukoba area (Table 2).

The initial success of the program seemed encouraging as the figures for the Arusha district (Mwasora, 1969) indicate (Tablc 3). However, until the end of 1969 the program was not totally effective and difficulties were met in controlling acaricide strengths, in collection of fees, and adequate coverage of the cattle populations.

To speed up the program, the government has now assumed operations of all district council dips and the regulation and supervision of private dips. As of January 1, 1970 the dipping of cattle is a free service provided by the government but complete cooperation is expected and therefore the dipping is compulsory.

The original government program lists some official rules for a dip site survey: One, the selected sites must be technically and administratively suitable. Two, the dips must be sited near permanent water sources where a continuous water supply is assured. Three, accessibility of the sites from passable roads must be considered to ensure that vehicles transporting construction materials can reach the site with ease. These rules indicate a tendency to install dips near already heavy cattle population concentrations.

Recently, an important consideration is added obviously with the grassland use in mind. The new policy is to site dips wherever water is available regardless of the distance between dips, although no two dips can be sited at a distance less than $6.5 \mathrm{~km}$ apart. This is an important step for bettcr distribution of cattle over the range. To cite a specific example, in south Masailand the range development commission supported by U.S.AID technicians believes that the building of dips has priority over other range improvement practices and 
Table 1. Summary of tick species that are causative agents for various diseases in cattle.

\begin{tabular}{lll}
\hline \hline \multicolumn{1}{c}{ Tick species } & \multicolumn{1}{c}{ Common name } & \multicolumn{1}{c}{ Cattle disease } \\
\hline Amblyomma variegatum & Tropical bont tick & Heartwater disease \\
Boophilus decoloratum & Blue tick & Anaplasmosis, Redwater disease \\
Hyalomma truncatum & African bont legged tick & Sweating sickness \\
Rhipicephalus appendiculatus & Brown ear tick & East Coast Fever \\
Rhipicephalus evertsii evertsii & Red legged tick & East Coast Fever, Redwater disease \\
\hline
\end{tabular}

Table 2. Contributions made toward the cost (Sh.) of dip installations.

\begin{tabular}{lc}
\hline \hline \multicolumn{1}{c}{ Source of contribution } & \multicolumn{1}{c}{ Cost } \\
\hline Average contribution by Distr. Council & $2750 / 00$ \\
Value of self-help by cattle owners & $77733 / 85$ \\
Ave. contribution by cattle owners & $2355 / 57$ \\
\hline
\end{tabular}

two dips have been constructed and are operating east of Kijungu $4.8 \mathrm{~km}$ apart (Fig. 1). Both are located near the Kijungu-Kibarashi road. Water is supplied from the Lolero springs by pipeline. The range is in fair condition. The two dips are capable of handling the cattle population in the area. However, the concentration of cattle for the use of the dips is placing a heavy burden on the grazing while an adjacent area to the north is getting little use. This area is in good condition with Cynodon plectostachyus, Panicum maximum, Eragrostis superba and Sporobolus fimbriatus the dominant grasses. There is also a high incidence of browse species which makes this area particularly suitable for dry season grazing. But the Masai herders only use this area sparingly and during the rainy season when depressions fill with water and tick populations are low.

Presently, the building of another dip is under consideration to open up this area for more intensive use. Funds are requested for the construction of a dip to include a watering trough. The water source is a small flow spring but temporary intensive use into the dry season is beneficial. With the dip operating to make

Table 3. Dipping figures since the start of the program, Arusha.

\begin{tabular}{crr}
\hline \hline & \multicolumn{2}{c}{ Numbers dipped } \\
\cline { 2 - 3 } Species & \multicolumn{1}{c}{1968} & \multicolumn{1}{c}{1969} \\
\hline Cattle & 394,669 & 528,673 \\
Goats & 7,765 & 11,019 \\
Sheep & 4,342 & 6,292 \\
Dogs & 367 & 915 \\
\hline
\end{tabular}

the area disease free the carrying capacity is increased and with proper grazing practices, healthy cattle keep the grass short thus undercutting a favorable lifecycle of the ticks.

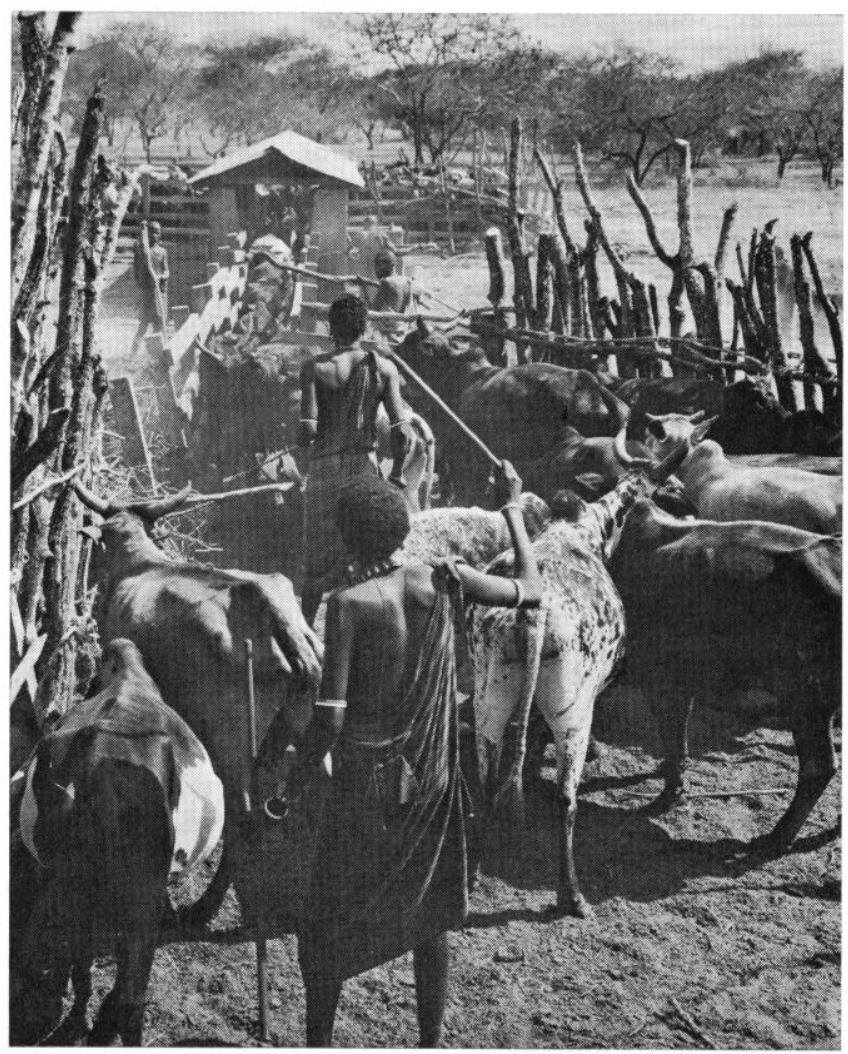

Fig. 1. Dip, operating near Kijungu, south Masailand. The cattle owners are eager to support the program.

\section{Literature Cited}

Mrema, J. L. 1969. History of the Bukoba dipping scheme between 1961 and 1967. Min. of Agr. Vet. Div. report, 24 October 1968, 23 p.

Mwasora, A. K. 1969. Arusha Distr. Annual dipping report 1969. Min. of Agr., Tanzania. 4 p.

Walker, J. B. 1962. Notes on the common tick species of east Africa. E. Afric. Vet. Res. Org. Kikuyu, Kenya. Publ. Cooper, McDougal \& Robertson (E.A.) Ltd., Nairobi. 23 p. 